\title{
Resenha \\ A Condição Humana Retratada pela Arte
}

\author{
The Human Condition Portrayed Through Art
}

Barroco, S. M. S. (2007).

Psicologia educacional e arte: Uma leitura histórico-cultural da figura humana. Maringá, SC: Editora da Universidade Estadual de Maringá.

\author{
Maria Lúcia Boarini* \\ Universidade Estadual de Maringá
}

"A criança não precisa de limites, apenas, mas também de referencias". Esta é, a nosso juízo, uma das mais significativas asserções da autora Sonia Mari Shima Barroco ao defender a idéia da arte pictórica, e em especial a representação da figura humana, como um importante recurso didático pedagógico a ser adotado no processo de ensino escolar.

A principio esta idéia pode nos parecer estranha, visto que a educação escolar e a Arte, sobretudo as telas dos grandes mestres da pintura, são tratadas, em geral, por segmentos diferentes da sociedade. Tradicionalmente a educação escolar é assunto para professores, pedagogos, psicólogos e outros profissionais afins. A não ser visitas esporádicas a museus, a eventuais exposições de arte que, diga-se de passagem, na maioria das vezes tomam o caráter de passeio, um momento para alunos e professores "livrarem-se" da rotina e do aperto físico das salas de aula, ou a realização de projetos isolados e descontinuados sobre algum artista famoso, nenhuma outra atividade no âmbito escolar faz lembrar a Arte existente ou mesmo a visitada. Sobre a instituição escolar vale lembrar que a rede de ensino escolar em solo brasileiro vem há décadas ocupando lugares nada recomendáveis no ranking internacional $^{1}$. Mais recentemente a escola também passou a ser assunto de notas policiais a considerar os fatos de caráter violento que vem se registrando a respeito envolvendo as relações dos alunos entre si, e destes com professores, no interior da instituição escolar, ou não. Isto sem contar a destruição ou saque dos prédios escolares. E, neste caso, nos parece desnecessário nos alongarmos com exemplos visto que a depredação do patrimônio publico vem se consti- tuindo em ponto de pauta de importantes jornais midiaticos.

No que tange a Arte produzida pelos mestres da pintura a questão é outra. Tudo é tratado com muito glamour. Nesta área nem de longe se pensa em depredação ou coisas do gênero, a não ser um caso ou outro de roubo, ocorrido esporadicamente, talvez, por vacilo do sistema de segurança onde as obras estão abrigadas. $\mathrm{O}$ assunto, via de regra, é tratado por curadores, museólogos, marchands, decoradores, proprietários de Galerias de Arte, profissionais conhecedores das mais requintadas técnicas de reconhecimento da originalidade, ou não, de uma obra de arte, além, é claro, dos colecionadores e estudiosos da arte. Vale notar que no glamour do mundo das artes, não importa quão miserável tenham sido as condições de vida do artista ao produzir suas telas. E, neste sentido, um dos exemplos mais emblemáticos é o caso de Vincent Van Gogh que sequer conseguiu vender uma de suas telas - o que lhe trouxe como conseqüência uma vida miserável, em termos financeiros. Mas isto não vem ao caso no mercado das obras de arte, que segue movimentando vultosas quantias. $\mathrm{O}$ forte esquema de segurança e cuidados no deslocamento destas obras de uma exposição à outra, por exemplo, nos dá a medida da valorização das obras que fazem parte deste mercado. Enfim, apesar de rápidas, estas pinceladas já nos possibilitam constatar que Arte e Educação parecem habitar mundos diferentes. Se fosse possível congelar as imagens teríamos de um lado a educação escolar tentando driblar os constantes fracassos de seus resultados e de outro lado o sofisticado mundo das Artes regozijando-se dos bons resultados a cada exposição realizada ou a cada leilão concluído.
*Endereço para correspondência: Universidade Estadual de Maringá, Centro de Ciências Humanas e Artes, Departamento de Psicologia, Av. Colombo, 5790, zona 7, Maringá, PR, Brasil, CEP 87020-900. Tel.: (44) 3261 4291; Fax: (44) 3261 4291. E-mail: mlboarini@uol.com.br

1 "A taxa de repetência no Brasil (21\%) se assemelha às de Moçambique e Eritréia, que possuem, respectivamente, o $168^{\circ}$ e o $161^{\circ} \mathrm{IDH}$ (índice que mede o desenvolvimento humano em todo o mundo). A lista tem 177 países - o Brasil é o $63^{\circ}$. Segundo o estudo, a repetência reflete 'condições insatisfatórias de ensino e de aprendizagem'. É o que aponta uma pesquisa divulgada ontem pela Unesco (Organização das Nações Unidas para a Educação, a Ciência e a Cultura). A entidade considerou os 45 países cujos índices de repetência são superiores a $10 \%$. O Brasil, com taxa de $21 \%$ (a pesquisa usa como base o ano de 2002), tem situação melhor apenas que 15 países, a maioria da África e do Caribe. O Camboja, por exemplo, tem 11\%. Já o Haiti, $16 \%$, e Ruanda, 19\%. No Chile, o índice é de 2\%, e na Argentina, 6\%." (Takahashi, 2006). 
Considerando o cenário exposto, desmistificar o dualismo cartesiano entre Educação e Arte é de maneira geral a proposta desta obra de autoria de Sonia Mari Shima Barroco. Valendo-se do método dialético Barroco recupera estudos de inspiração marxista (psicologia histórico-cultural, pedagogia histórico-critica) para sustentar teoricamente suas proposições. Proposições resultantes de um longo e amadurecido processo de investigação e análise que a autora realizou com telas que retratam figuras humanas produzidas, no período entre 1880-1960, por artistas brasileiros, reconhecidos nacional e/ou internacionalmente.

Percorrendo as telas de Almeida Junior (1850-1899), Lasar Segall (1891-1957), Anita Malfatti (1896-1964), Tarsila do Amaral (1857-1973), Di Cavalcanti (1897-1976), Ismael Nery (1900-1934), Candido Portinari (1903-1962), Milton Dacosta (1915-1988) Barroco vai conduzindo o leitor a uma outra forma de entender a arte pictórica. Por meio de raciocínio detalhista apresentado em linguagem clara e precisa a autora vai esmiuçando as possibilidades do entendimento do homem e do seu tempo nas figuras humanas estampadas nas telas. Revela que "o homem imprime sua própria historia nos produtos que cria e no modo como os faz". E vai além, "ao apropriar-se dos conteúdos, instrumentos e signos próprios de uma dada época e sociedade, cada sujeito, em particular, acaba reproduzindo, em nível individual, as formas sociais e históricas da atividade humana". Assim, este homem reproduzido nas telas não se refere apenas às idiossincrasias do artista, embora não há como negá-las. Esta figura revela também a historicidade da condição humana que não se explica sem os dados do mundo objetivo, exterior. No exercício metodológico na construção de suas análises Barroco explicita a pertinência da utilização da figura humana retratada nas telas como um dos caminhos que nos levam a pensar nas condições vividas e produzidas pelo Homem. Garante, nestes termos, a coerência com o arcabouço teórico-conceitual sobre o qual se apóia. Pagina por pagina, recorrendo a inúmeras e variadas ilustrações, Barroco coloca em destaque a parceria entre Arte e Educação bem como a Ciência, a Filosofia como importantes referencias no processo pedagógico. Dentre as ilustrações, nos entremeios da análise a autora confessa que o estudo destas telas propiciou-lhe alterações em seu próprio entendimento, "isto porque o conhecimento adquirido por meio das obras ultrapassa a simples descrição linear e factual das características evidenciadas. A Arte depende de símbolos que transcendem a esfera imediata da interpretação literal.". Analisadas sob este ângulo, a figura humana retratada nas telas é uma forma de ampliar "o caminho para se pensar o comportamento humano". Ao se referir ao comportamento humano, Barroco aproxima-se da área de conhecimento da psicologia, em especial as técnicas de projeção que se valem do desenho da figura humana. Técnicas que constam da grade curricular dos cursos de psicologia e pelo seu caráter avaliativo são frequentemente empregadas pelo psicólogo nas mais diferentes situações (em clinicas particulares, na avaliação de escolares, no setor de Recursos Humanos das empresas, no setor de Trânsito, etc.). Mesclando suas análises com uma pitada de ironia Barroco demonstra a fragilidade das análises produzidas pelos psicólogos a partir do desenho da figura humana quando perde de vista a historicidade do homem. São reflexões deveras provocativas. A autora reconhece que uma pessoa pode possibilitar o desvelar de seus aspectos subjetivos por intermédio de seu desenho da figura humana. Aspectos, talvez, de difícil acesso por outras vias de manifestação (verbal oral ou escrita, gestual, etc.). Não obstante, chama a atenção do leitor para a socialidade contida em cada figura humana desenhada. Pontua, de maneira recorrente, quão frágeis são as análises do psiquismo a partir de figuras humanas circunscritas à biografia do seu autor, emancipadas do seu tempo e da sociedade em que vive e é enfática ao afirmar:

É inquietante a manifestação dessa perspectiva junto à Educação, visto que tem faltado o estabelecimento de 'conexões' com a realidade, com outras áreas do conhecimento e até com as próprias emoções que a experiência estética pode suscitar para lidar com os indivíduos reais. Essas ‘conexões' podem garantir novas formas de 'sentir' o homem e o mundo e de com eles 'interagir'. (Barroco, 2007, p. 187).

Enfim, a leitura desta obra nos coloca diante de um paradoxo, ou seja, é uma leitura fácil, agradável e ao mesmo tempo provocativa, instigante, convincente, inclusive da necessidade do redimensionamento das questões epistemológicas no processo de formação do psicólogo e na interlocução deste profissional com a Educação.

A titulo de conclusão, retornamos a frase que deu inicio a este texto "A criança não precisa de limites, apenas, mas também de referencias". A leitura desta obra nos convida a pensar que o adulto não foge a regra e também precisa de referencias. É o que Barroco deixa implícito em toda obra.

\section{Referências}

Barroco, S. M. S. (2007). Psicologia educacional e arte: Uma leitura histórico-cultural da figura humana. Maringá, SC: Editora da Universidade Estadual de Maringá.

Takahashi, F. (2006, 26 abr.). País tem repetência maior do que o Camboja. Folha de São Paulo. Retrieved June 16, 2008, from http://www1.folha.uol.com.br/folha/educacao/ult305 u18571.shtml 